\title{
Effect of the Electrolyte Temperature and the Current Density on a Layer Microhardness Generated by the Anodic Aluminium Oxidation
}

\author{
Emil Spišák, ${ }^{1}$ Miroslav Gombár, ${ }^{2}$ Ján Kmec, ${ }^{2}$ Alena Vagaská, ${ }^{3}$ Erika Fechová, ${ }^{3}$ \\ Peter Michal, ${ }^{3}$ Ján Pitel', ${ }^{3}$ and Daniel Kučerka ${ }^{2}$ \\ ${ }^{1}$ Department of Technologies and Materials, Faculty of Mechanical Engineering, Technical University of Košice, Mäsiarska 74, \\ 04200 Košice, Slovakia \\ ${ }^{2}$ The Department of Mechanical Engineering, Institute of Technology and Businesses in České Budějovice, Okružní 10, \\ 37001 Ceské Budéjovice, Czech Republic \\ ${ }^{3}$ Department of Mathematics, Informatics and Cybernetics, Faculty of Manufacturing Technologies with a Seat in Prešov, \\ Technical University of Košice, Bayerova 1, 08001 Prešov, Slovakia
}

Correspondence should be addressed to Erika Fechová; erika.fechova@tuke.sk

Received 24 September 2014; Revised 19 March 2015; Accepted 23 March 2015

Academic Editor: Markku Leskela

Copyright (C) 2015 Emil Spišák et al. This is an open access article distributed under the Creative Commons Attribution License, which permits unrestricted use, distribution, and reproduction in any medium, provided the original work is properly cited.

\begin{abstract}
The paper investigates the influence of the chemical composition and temperature of electrolyte, the oxidation time, voltage, and the current density on Vickers microhardness of aluminium oxide layers, at the same time. The layers were generated in the electrolytes with different concentrations of sulphuric and oxalic acids and surface current densities $1 \mathrm{~A} \cdot \mathrm{dm}^{-2}, 3 \mathrm{~A} \cdot \mathrm{dm}^{-2}$, and $5 \mathrm{~A} \cdot \mathrm{dm}^{-2}$. The electrolyte temperature varied from $-1.78^{\circ} \mathrm{C}$ to $45.78^{\circ} \mathrm{C}$. The results have showed that while increasing the electrolyte temperature at the current density of $1 \mathrm{~A} \cdot \mathrm{dm}^{-2}$, the increase in the layer microhardness values is approximately by $66 \%$. While simultaneously increasing the molar concentration of $\mathrm{H}_{2} \mathrm{SO}_{4}$ in the electrolyte, the growth rate of the microhardness value decreases. At the current density of $3 \mathrm{~A} \cdot \mathrm{dm}^{-2}$, by increasing the electrolyte temperature, a reduction in the microhardness of the generated layer occurs with the anodic oxidation time less than $25 \mathrm{~min}$. The electrolyte temperature is not significant with the changing values of the layer microhardness at voltages less than $10.5 \mathrm{~V}$.
\end{abstract}

\section{Introduction}

Properties of the surface layers generated by the anodic aluminium oxide (AAO), such as a high surface hardness of the layer, corrosion resistance $[1,2]$, and wear resistance predetermine aluminium products treated in that manner for a widespread application not only in the traditional fields of engineering, transport, and construction but also for a potential utilisation in magnetic recording media [3], photovoltaic solar cells [4], filters [5], chemical sensors [6], photonics [7], and metal nanowires [8, 9].

The majority of experimental operations in the field of (micro) hardness are carried out in "difficult" conditions of the anodizing. Here we can include low temperatures of the electrolyte and often also a special chemical composition of electrolytes. Their primary objective is to achieve high values of the layers microhardness. According to Scott [10], who, for the anodic oxidation in sulfuric acid at the constant current density of $4 \mathrm{~A} \cdot \mathrm{dm}^{-2}$, was changing the temperature from $-5^{\circ} \mathrm{C}$ to $15^{\circ} \mathrm{C}$, the microhardness under these conditions is affected to a small extent, which is also related to wear resistance. Another study published by Koizumi et al. [11] deals with the anodic oxidation of aluminium in a galvanostatic regime. The current densities from 1 to $8 \mathrm{~A} \cdot \mathrm{dm}^{-2}$ were used; the electrolyte was constituted by sulfuric acid and oxalic acid. The electrolyte temperatures ranged from $-5^{\circ} \mathrm{C}$ to $20^{\circ} \mathrm{C}$. Koizumi et al. [11] argue that the microhardness and wear resistance are almost constant in the temperature interval $-5^{\circ} \mathrm{C}$ to $5^{\circ} \mathrm{C}$ regardless of the applied current density. Furthermore, this study argues that the increase in 
TABLE 1: Chemical composition of the experimental material in wt.\%.

\begin{tabular}{lcccccc}
\hline $\mathrm{Si}$ & $\mathrm{Fe}$ & $\mathrm{Cu}$ & $\mathrm{Mn}$ & $\mathrm{Cr}$ & $\mathrm{Zn}$ & $\mathrm{Ti}$ \\
\hline 0.25 & 0.40 & 0.05 & 0.01 & 0.01 & 0.07 & 0.05 \\
\hline
\end{tabular}

the electrolyte temperature leads to a gradual reduction in the microhardness value. A more significant decrease in the microhardness occurs when using lower values of the current density. This statement, however, should be treated with reserve, since the time of anodic oxidation in this experiment was always constant, that is, 45 minutes, regardless of the used current densities. As a result, layers of a larger thickness were generated and subsequently evaluated. The thickness of the generated layer directly affects the resulting values of microhardness and wear resistance [12-14].

AAO layers with the thickness of $25 \mu \mathrm{m}$ or more, generated in the electrolyte constituted by sulfuric acid at the temperatures within the interval $15^{\circ} \mathrm{C}$ up to $30^{\circ} \mathrm{C}$ and at different values of the applied current densities ( 1 to $4 \mathrm{~A} \cdot \mathrm{dm}^{-2}$ ), according to some authors [15] have a softer outer layer, which reduces the transparency of the layer as well as its microhardness and wear resistance. Based on the publication [16], it was observed that the pores size is affected by the voltage, the electrolyte temperature, and the anodic oxidation time. A vertical growth of pores $\left(10-250 \mathrm{~nm} \cdot \mathrm{min}^{-1}\right)$ is exponentially dependent on the voltage and linearly it is dependent on the change in the electrolyte temperature. On the other hand, the pores diameter $(50-130 \mathrm{~nm})$ exhibits a linear change along with the applied voltage. The size and the number of pores strongly influence the layer microhardness. The work [17], which deals with the reanodization, in an effort to derive kinetics experimentally based on the calculated dependencies, concludes that the available values of the constants depending on the intensity of the electric field and the temperature are not applicable to the anodic oxidation at high current densities. The increase in the temperature inside the generated layer is given as a possible explanation.

The aim of the authors is to analyze experimentally the dependence of the layer microhardness along with the changing temperature of the electrolyte and the current density. Surface treatment processes are complex multifactor systems with a significant interactions effect. These interactions usually appear more significant than the effect of individual factors. Therefore, the microhardness is analyzed also with regard to the impact of other operating factors. Thus, it is possible to come to more accurate conclusions and recommendations.

\section{Experimental}

Aluminium sheet EN AW-1050 A-H24 of the thickness of $0.5 \mathrm{~mm}$ was used as an experimental anode material. The chemical composition of the experimental material is shown in Table 1.

The samples with dimensions $100 \times 70 \times 0,5 \mathrm{~mm}$ were chemically degreased in a solution containing sodium bicarbonate $<20 \%$, sodium metasilicate pentahydrate $<5 \%$, phosphates $<30 \%$, borates $<40 \%$, and surfactants $<5 \%$, at the temperature of $50 \pm 2^{\circ} \mathrm{C}$ for a total exposure time of 15 minutes. The samples were then rinsed thoroughly in deionized water and immersed in a $45 \%$ sodium hydroxide solution at the temperature of $55 \pm 2^{\circ} \mathrm{C}$ for $1 \mathrm{~min}$. The anodizing was performed based on the Design of Experiments methodology corresponding to the rotatable central composite design with 44 test runs. The individual runs were carried out according to the design of experiment as a combination of factor levels corresponding with Table 2.

After anodizing, the samples were immediately rinsed in cooled (approximately $10^{\circ} \mathrm{C}$ ) demiwater for 1 minute, followed by rinsing in running tap water for another 2 minutes to wash out the electrolyte entrapped in the defects. The specimens were thereafter dried with compressed air and in an oven (at the temperature of $50^{\circ} \mathrm{C}$, in the course of 20 minutes).

In the field of the surface treatment, the Hull cell is mostly used to verify the electrolyte functionality and a chemical composition of the electrolyte. The Hull cell, in a rectangular trapezium shape with the dimensions corresponding to Figure 1, was used for both performed experiments. Figure 1 also shows the experimental apparatus connection, which includes an adjustable DC power source (continuous voltage control from 0 to $20 \mathrm{~V}$ ), an ammeter to control the measurement of a direct current flowing through an electric circuit (the current regulation from 0 to $5 \mathrm{~A}$ ), and a voltmeter for measuring the total voltage.

\section{Results and Discussions}

The initial experiment was conducted to identify the basic physical effects such as the voltage, the electrolyte temperature, and a total current. A graphical representation of time dependence is in Figure 2.

The graph (Figure 2(a)) shows that the time variation of the total current is strongly dependent on the electrolyte temperature. Kinetics of the anodic layer growth can be seen in Figure 2(b), which represents the time dependence of the flowing current. The first 30 seconds are an important time interval when a poreless barrier layer is formed. The first stage is characterized by a sharp increase in the value of the total current in a very short time and its subsequent decline. Here, the increase of the anodic potential occurs. At this stage, the germs of oxide cells and a surface barrier oxide layer are formed. The first cells are formed in the locations of the boundaries nodes between the crystals of the aluminium surface [18]. Other oxide cells are formed along these boundaries. The formation of oxide cells at these locations is due to a higher chemical potential of these areas and a high concentration of crystallographic defects. At the end of this stage, there is a regrowth of the total current and a decrease in the anodic potential. The quantity of oxide cells decreases in this phase. At the same time there is the increase in their size by the mechanism of a "competition" (enlargement of cells dimensions at the expense of others, nonperspective). At the same time, a thickening of cells distribution and thereby a reduction of noncellular areas of 
TABLE 2: Conditions of the performed experiment.

\begin{tabular}{lcccccc}
\hline Factor code & \multirow{2}{*}{ Factor } & Unit & \multicolumn{3}{c}{ Factor level } \\
& & & -2.37 & -1 & 0 & +1 \\
\hline$x_{1}$ & $c\left(\mathrm{H}_{2} \mathrm{SO}_{4}\right)$ & $\mathrm{mol} \cdot \mathrm{l}^{-1}$ & 0.09 & 0.87 & 1.43 & 1.99 \\
$x_{2}$ & $c\left(\mathrm{C}_{2} \mathrm{H}_{2} \mathrm{O}_{4}\right)$ & $\mathrm{mol} \cdot \mathrm{l}^{-1}$ & 0.06 & 0.13 & 0.18 & 0.23 \\
$x_{3}$ & $T$ & ${ }^{\circ} \mathrm{C}$ & -1.78 & 12 & 22 & 0.30 \\
$x_{4}$ & $t$ & $\mathrm{~min}$ & 1.22 & 15 & 25 & 32 \\
$x_{5}$ & $U$ & $\mathrm{~V}$ & 6.43 & 8.5 & 10 & 35 \\
\hline
\end{tabular}

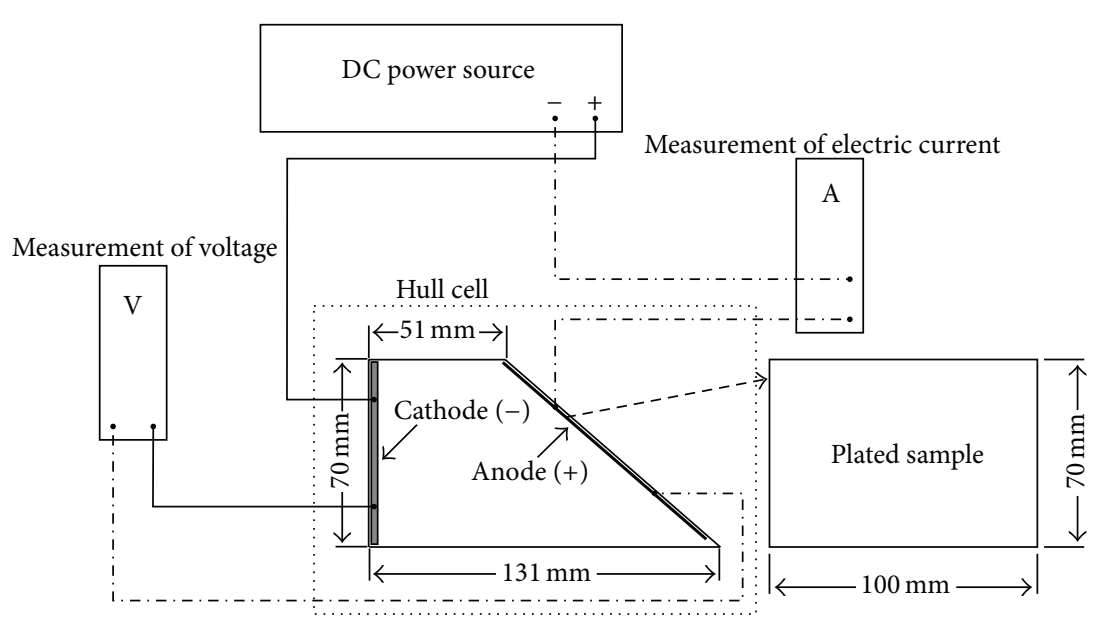

Figure 1: Connection diagram of the experimental apparatus.

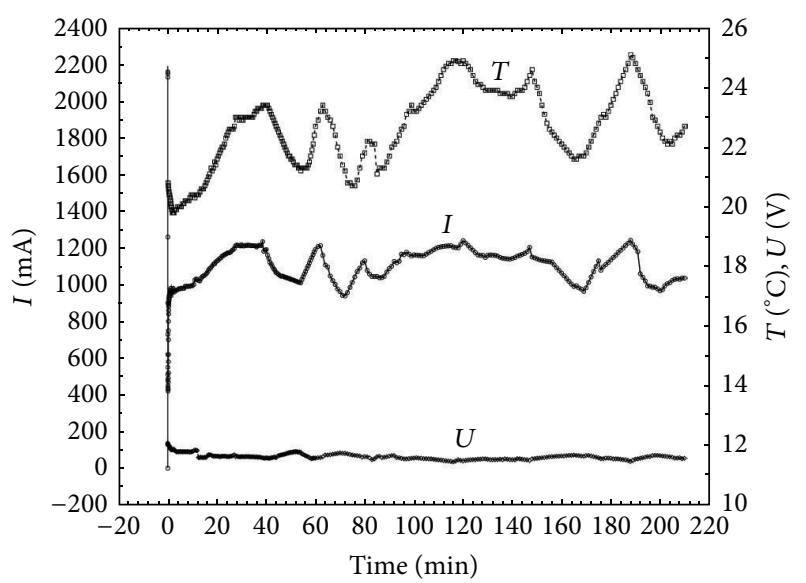

(a)

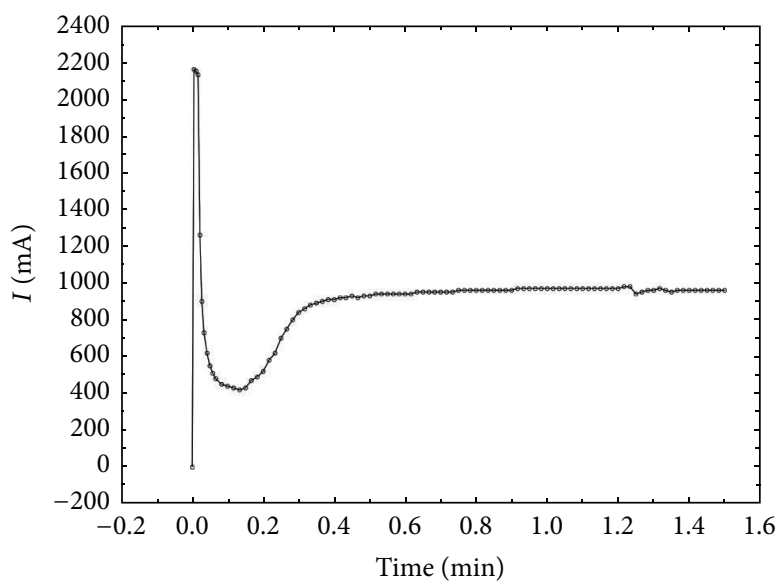

(b)

Figure 2: The time course of the voltage, current, and temperature during the anodic oxidation in sulfuric acid and oxalic acid at the temperature of $12^{\circ} \mathrm{C}$, the voltage of $12 \mathrm{~V}$ : (a) $t=210 \mathrm{~min}$, (b) $t=1.5 \mathrm{~min}$.

the barrier oxide layer take place. At this stage, there is no longer a sharp drop in the anode potential. The dimensions of oxide cells grow, but the rate of this process is substantially reduced. In the third stage, which is characterized by a steady current value as well as the anode potential value, the anodically oxidized layer increases considering its thickness and the layer has a porous structure (Figure 3 ).

The analysis of the values of the layers microhardness generated by the anodic aluminium oxidation in dependence on the temperature is shown in Figures 4-12. Within the experimental analysis, the effect of other operating factors on the changes in the microhardness value is evaluated. In Figure 4, with the current density of $1 \mathrm{~A} \cdot \mathrm{dm}^{-2}$, a strongly nonlinear dependence of the layer microhardness on the electrolyte temperature can be observed.

Within the range of the electrolyte temperature from -1.5 to $8.5^{\circ} \mathrm{C}$, a reduced microhardness of the layer occurs. This decrease can be attributed to a low voltage as well as 


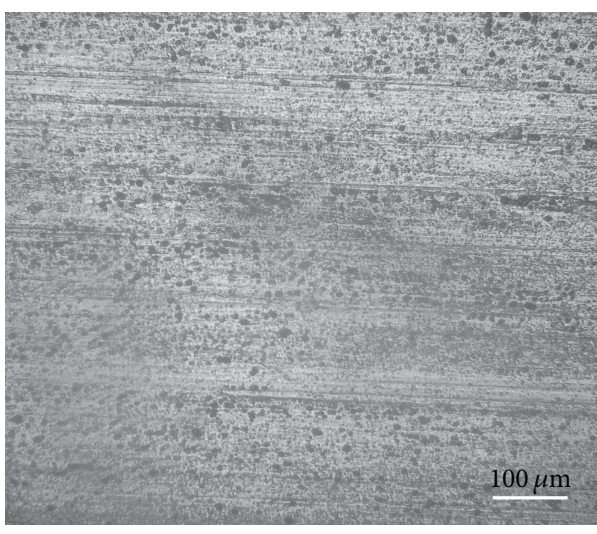

(a)

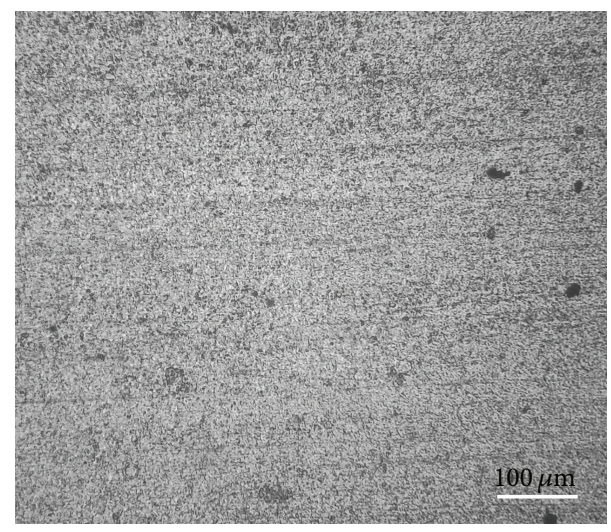

(b)

FIGURE 3: The layer surface structure: (a) $c\left(\mathrm{H}_{2} \mathrm{SO}_{4}\right)=0.87 \mathrm{~mol} \cdot \mathrm{L}^{-1}, c\left(\mathrm{C}_{2} \mathrm{H}_{2} \mathrm{O}_{4}\right)=0.13 \mathrm{~mol} \cdot \mathrm{L}^{-1}, T=12^{\circ} \mathrm{C}, U=8.5 \mathrm{~V}, t=15 \mathrm{~min} .(\mathrm{b}) c\left(\mathrm{H}_{2} \mathrm{SO} \mathrm{O}_{4}\right)=$ $0.87 \mathrm{~mol} \cdot \mathrm{L}^{-1}, c\left(\mathrm{C}_{2} \mathrm{H}_{2} \mathrm{O}_{4}\right)=0.13 \mathrm{~mol} \cdot \mathrm{L}^{-1}, T=32^{\circ} \mathrm{C}, U=11.5 \mathrm{~V}, t=35 \mathrm{~min}$.

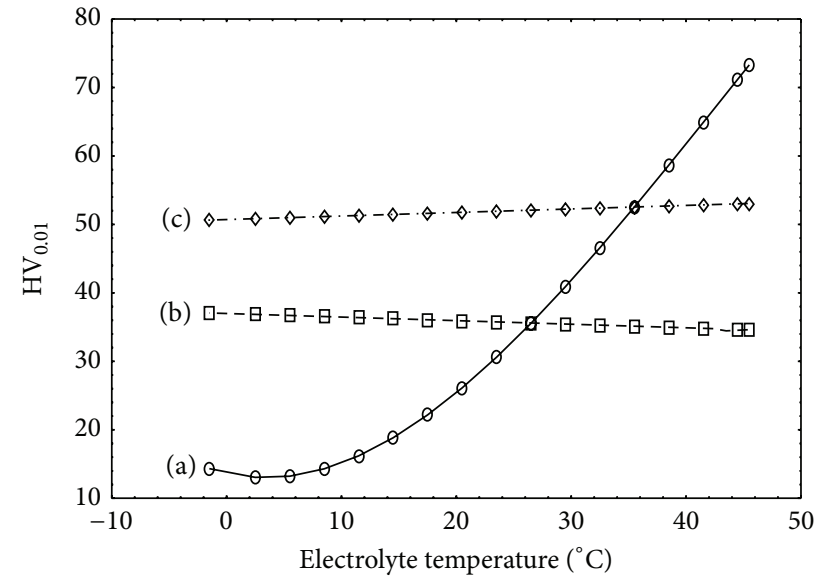

FIgURE 4: The dependence of the layer microhardness on the temperature of the electrolyte: $c\left(\mathrm{H}_{2} \mathrm{SO}_{4}\right)=0.09 \mathrm{~mol} \cdot \mathrm{L}^{-1}, c\left(\mathrm{C}_{2} \mathrm{H}_{2} \mathrm{O}_{4}\right)=$ $0.06 \mathrm{~mol} \cdot \mathrm{L}^{-1}, U=10 \mathrm{~V}, t=15 \mathrm{~min}$. (a) $1 \mathrm{~A} \cdot \mathrm{dm}^{-2}$, (b) $3 \mathrm{~A} \cdot \mathrm{dm}^{-2}$, and (c) $5 \mathrm{~A} \cdot \mathrm{dm}^{-2}$.

a low value of the molar concentration of $\mathrm{H}_{2} \mathrm{SO}_{4}$. The rise in the electrolyte temperature over $8.5^{\circ} \mathrm{C}$ leads to a sharp rise in the value of the layer microhardness. Within the interval of the electrolyte temperature $11.5^{\circ} \mathrm{C}$ to $45.5^{\circ} \mathrm{C}$, there will be an increase in the microhardness of the layer of $78 \%$. At the current densities of $3 \mathrm{~A} \cdot \mathrm{dm}^{-2}$ and $5 \mathrm{~A} \cdot \mathrm{dm}^{-2}$, the electrolyte temperature does not significantly affect the value of the layer microhardness. At $3 \mathrm{~A} \cdot \mathrm{dm}^{-2}$, the increase in the temperature of the electrolyte causes even the layer microhardness reduction of $7 \%$. At the current density of $5 \mathrm{~A} \cdot \mathrm{dm}^{-2}$, a slight increase in the layer microhardness of about $4 \%$ is observed.

The dependence of microhardness on the electrolyte temperature with the increasing molar concentration of sulfuric acid to $1.43 \mathrm{~mol} \cdot \mathrm{L}^{-1}$ is in Figure 5. Here we can also observe the area of the minimum values of the layer microhardness at the current density of $1 \mathrm{~A} \cdot \mathrm{dm}^{-2}$. The absolute value of the layer microhardness in the area of minimum (1.5 to

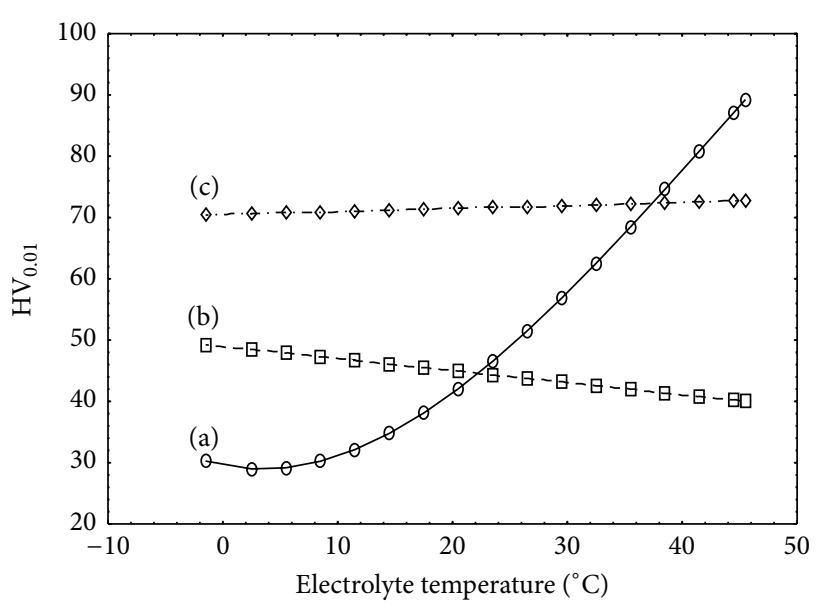

FIgURE 5: The dependence of the layer microhardness on the temperature of the electrolyte: $c\left(\mathrm{H}_{2} \mathrm{SO}_{4}\right)=1.43 \mathrm{~mol} \cdot \mathrm{L}^{-1}, c\left(\mathrm{C}_{2} \mathrm{H}_{2} \mathrm{O}_{4}\right)=$ $0.06 \mathrm{~mol} \cdot \mathrm{L}^{-1}, U=10 \mathrm{~V}, t=15 \mathrm{~min}$. (a) $1 \mathrm{~A} \cdot \mathrm{dm}^{-2}$, (b) $3 \mathrm{~A} \cdot \mathrm{dm}^{-2}$, and (c) $5 \mathrm{~A} \cdot \mathrm{dm}^{-2}$.

$8.5^{\circ} \mathrm{C}$ ) is on average nearly $30 \%$. The increasing molar concentration of $\mathrm{H}_{2} \mathrm{SO}_{4}$ from $0.09 \mathrm{~mol} \cdot \mathrm{L}^{-1}$ to $1.43 \mathrm{~mol} \cdot \mathrm{L}^{-1}$, in low temperatures areas, results in the increase in the layer microhardness of almost $54 \%$ at the current density of $1 \mathrm{~A} \cdot \mathrm{dm}^{-2}$. At the current density of $3 \mathrm{~A} \cdot \mathrm{dm}^{-2}$, a decrease in the layer microhardness with the increasing electrolyte temperature can be observed. This decline in the value of microhardness is $23 \%$. The microhardness decrease compared to the electrolyte with $c\left(\mathrm{H}_{2} \mathrm{SO}_{4}\right)=0.09 \mathrm{~mol} \cdot \mathrm{L}^{-1}$ is almost $16 \%$. The development of the layer microhardness at the current density of $5 \mathrm{~A} \cdot \mathrm{dm}^{-2}$ can be considered constant. The temperature of the electrolyte has no significant effect on the layer microhardness at the current density of $5 \mathrm{~A} \cdot \mathrm{dm}^{-2}$.

A further increase in the molar concentration of sulfuric acid to $2.76 \mathrm{~mol} \cdot \mathrm{L}^{-1}$ (Figure 6) at the current density of $1 \mathrm{~A} \cdot \mathrm{dm}^{-2}$ results in the extension of the areas of minimum values and the increase in the average value of microhardness. 


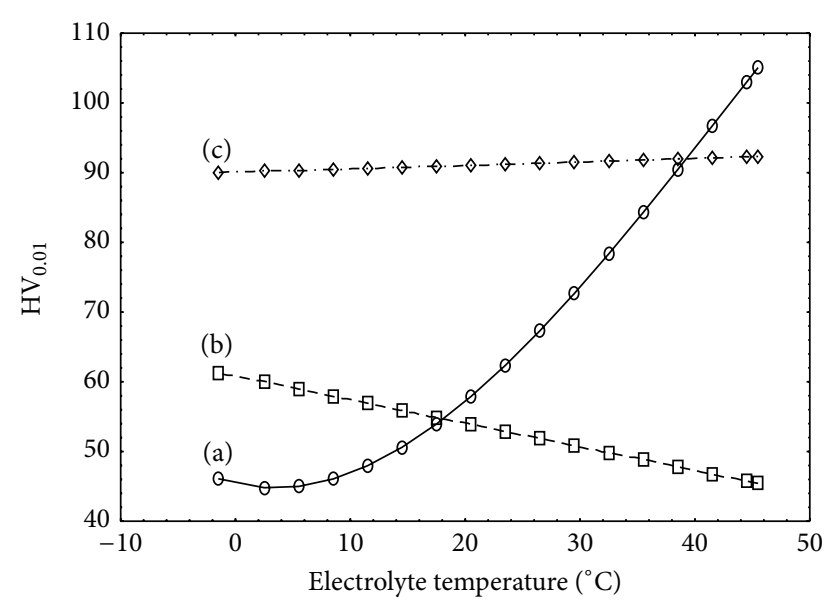

Figure 6: The dependence of the layer microhardness on the temperature of the electrolyte: $c\left(\mathrm{H}_{2} \mathrm{SO}_{4}\right)=2.76 \mathrm{~mol} \cdot \mathrm{L}^{-1}, c\left(\mathrm{C}_{2} \mathrm{H}_{2} \mathrm{O}_{4}\right)=$ $0.06 \mathrm{~mol} \cdot \mathrm{L}^{-1}, U=10 \mathrm{~V}, t=15 \mathrm{~min}$. (a) $1 \mathrm{~A} \cdot \mathrm{dm}^{-2}$, (b) $3 \mathrm{~A} \cdot \mathrm{dm}^{-2}$, and (c) $5 \mathrm{~A} \cdot \mathrm{dm}^{-2}$.

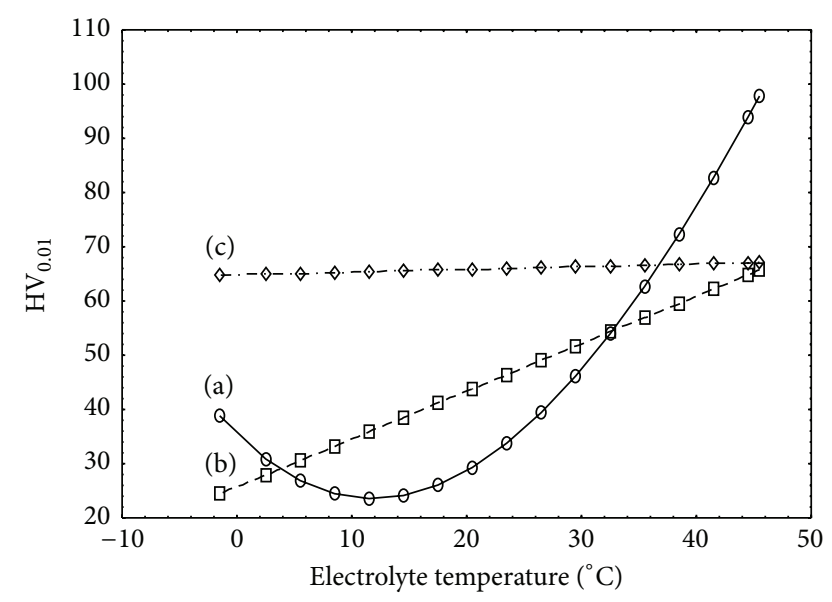

FIgURE 7: The dependence of the layer microhardness on the temperature of the electrolyte: $c\left(\mathrm{H}_{2} \mathrm{SO}_{4}\right)=1.43 \mathrm{~mol} \cdot \mathrm{L}^{-1}, c\left(\mathrm{C}_{2} \mathrm{H}_{2} \mathrm{O}_{4}\right)=$ $0.06 \mathrm{~mol} \cdot \mathrm{L}^{-1}, U=10 \mathrm{~V}, t=1.22 \mathrm{~min}$. (a) $1 \mathrm{~A} \cdot \mathrm{dm}^{-2}$, (b) $3 \mathrm{~A} \cdot \mathrm{dm}^{-2}$, and (c) $5 \mathrm{~A} \cdot \mathrm{dm}^{-2}$.

The area of the minimum is extended from 1.5 to $11.5^{\circ} \mathrm{C}$. The average value of microhardness compared to the electrolyte with $c\left(\mathrm{H}_{2} \mathrm{SO}_{4}\right)=1.43 \mathrm{~mol} \cdot \mathrm{L}^{-1}$ is increased by $36 \%$. At the current density of $3 \mathrm{~A} \cdot \mathrm{dm}^{-2}$, a significant decrease in the layer microhardness is observed depending on the electrolyte temperature. This decrease is $35 \%$. The increase in the absolute average value of the layer microhardness compared to the electrolyte with $c\left(\mathrm{H}_{2} \mathrm{SO}_{4}\right)=1.43 \mathrm{~mol} \cdot \mathrm{L}^{-1}$, at the current density of $3 \mathrm{~A} \cdot \mathrm{dm}^{-2}$, is on average $12 \%$. At the electrolyte temperature of $-1.5^{\circ} \mathrm{C}$, the difference of the microhardness values is $20 \%$. With the increasing temperature of the electrolyte, the difference declines to the value of $12 \%$ at the temperature of $45.5^{\circ} \mathrm{C}$. At the current density of $5 \mathrm{~A} \cdot \mathrm{dm}^{-2}$, only a slight increase in the layer microhardness in dependence on the electrolyte temperature is observed. The value of the increase is $2.5 \%$.

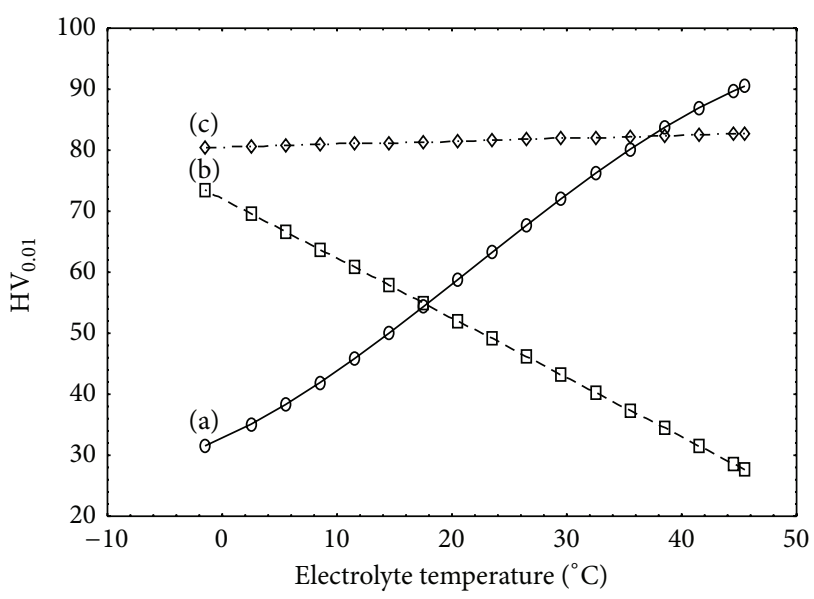

Figure 8: The dependence of the layer microhardness on the temperature of the electrolyte: $c\left(\mathrm{H}_{2} \mathrm{SO}_{4}\right)=1.43 \mathrm{~mol} \cdot \mathrm{L}^{-1}, c\left(\mathrm{C}_{2} \mathrm{H}_{2} \mathrm{O}_{4}\right)=$ $0.06 \mathrm{~mol} \cdot \mathrm{L}^{-1}, U=10 \mathrm{~V}, t=25 \mathrm{~min}$. (a) $1 \mathrm{~A} \cdot \mathrm{dm}^{-2}$, (b) $3 \mathrm{~A} \cdot \mathrm{dm}^{-2}$, and (c) $5 \mathrm{~A} \cdot \mathrm{dm}^{-2}$.

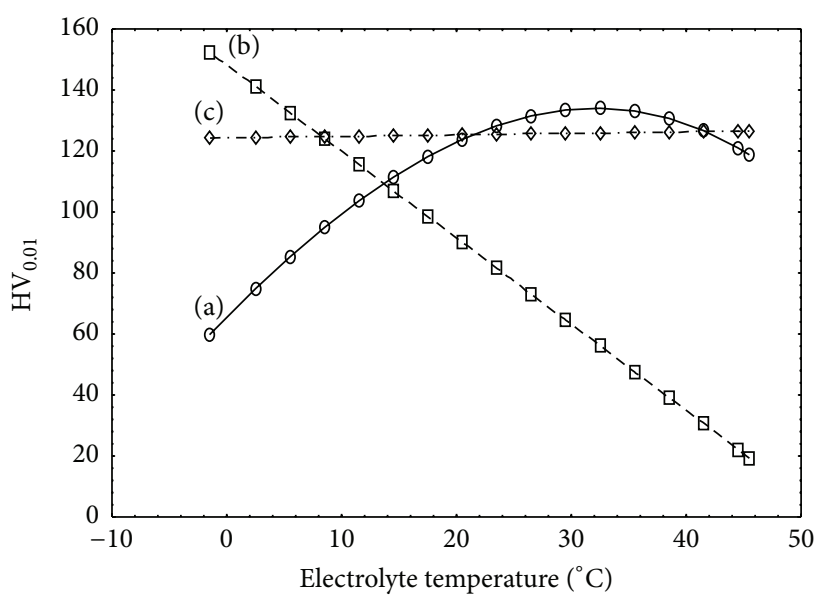

FIGURE 9: The dependence of the layer microhardness on the temperature of the electrolyte: $c\left(\mathrm{H}_{2} \mathrm{SO}_{4}\right)=1.43 \mathrm{~mol} \cdot \mathrm{L}^{-1}, c\left(\mathrm{C}_{2} \mathrm{H}_{2} \mathrm{O}_{4}\right)=$ $0.06 \mathrm{~mol} \cdot \mathrm{L}^{-1}, U=10 \mathrm{~V}, t=48.78 \mathrm{~min}$. (a) $1 \mathrm{~A} \cdot \mathrm{dm}^{-2}$, (b) $3 \mathrm{~A} \cdot \mathrm{dm}^{-2}$, and (c) $5 \mathrm{~A} \cdot \mathrm{dm}^{-2}$.

Based on the analysis, the electrolyte temperature is the significant factor with the current density of $1 \mathrm{~A} \cdot \mathrm{dm}^{-2}$. It is also the most important factor that affects the layer microhardness. The share of the temperature in the total variability of the microhardness values is $14 \%$. A strong dependence of the layer microhardness on the electrolyte temperature is also reflected in the interaction with the molar concentration of sulfuric acid in the electrolyte. With a concurrent increase in the temperature of the electrolyte and the molar concentration of sulfuric acid, the mean value of microhardness increases. This is due to the nature of the anodic oxidation. When developing the porous oxide layers, there exist two parallel reactions in the same system: one for the electrochemical, anodic formation of a metal oxide 


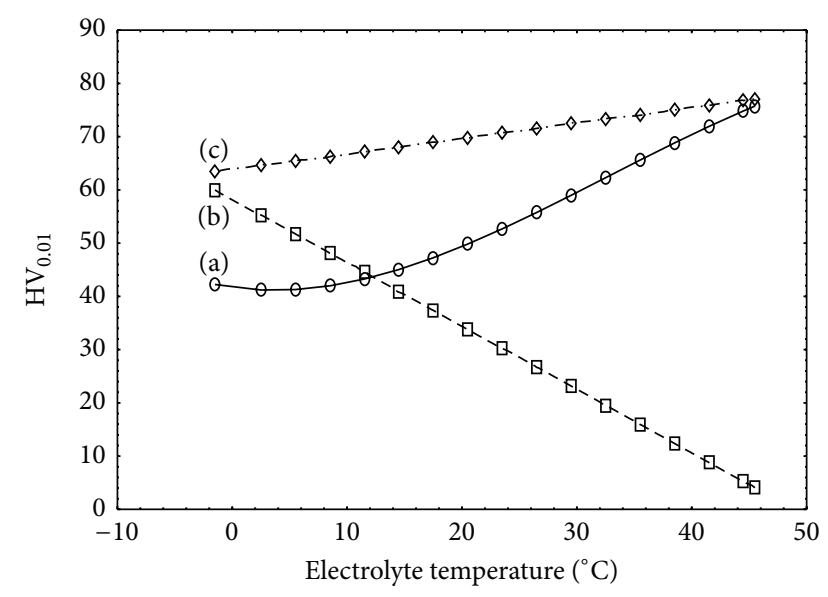

FIgURE 10: The dependence of the layer microhardness on the electrolyte temperature: $c\left(\mathrm{H}_{2} \mathrm{SO}_{4}\right)=1.99 \mathrm{~mol} \cdot \mathrm{L}^{-1}, c\left(\mathrm{C}_{2} \mathrm{H}_{2} \mathrm{O}_{4}\right)=$ $0.06 \mathrm{~mol} \cdot \mathrm{L}^{-1}, U=8.5 \mathrm{~V}, t=20 \mathrm{~min}$. (a) $1 \mathrm{~A} \cdot \mathrm{dm}^{-2}$, (b) $3 \mathrm{~A} \cdot \mathrm{dm}^{-2}$, and (c) $5 \mathrm{~A} \cdot \mathrm{dm}^{-2}$.

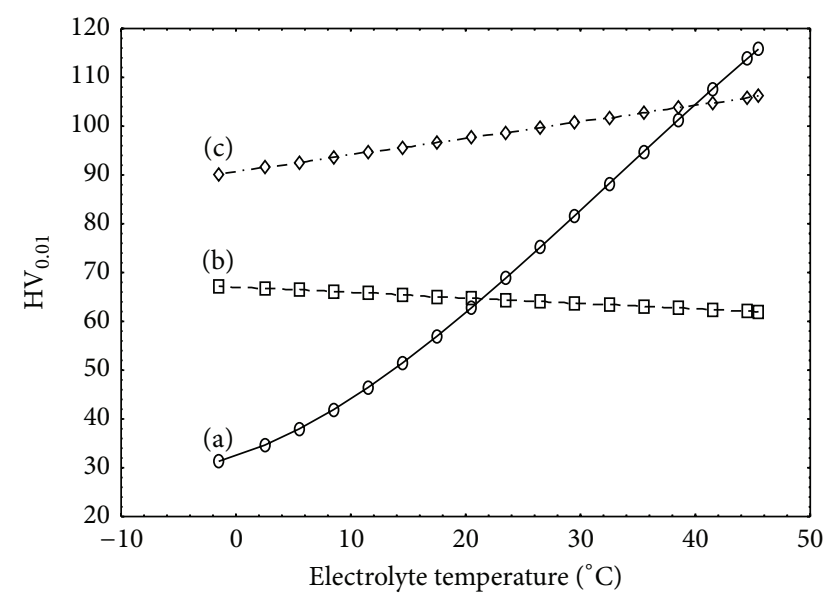

Figure 11: The dependence of the layer microhardness on the temperature of the electrolyte: $c\left(\mathrm{H}_{2} \mathrm{SO}_{4}\right)=1.99 \mathrm{~mol} \cdot \mathrm{L}^{-1}, c\left(\mathrm{C}_{2} \mathrm{H}_{2} \mathrm{O}_{4}\right)=$ $0.06 \mathrm{~mol} \cdot \mathrm{L}^{-1}, U=10.5 \mathrm{~V}, t=20 \mathrm{~min}$. (a) $1 \mathrm{~A} \cdot \mathrm{dm}^{-2}$, (b) $3 \mathrm{~A} \cdot \mathrm{dm}^{-2}$, and (c) $5 \mathrm{~A} \cdot \mathrm{dm}^{-2}$.

$\left(\mathrm{MeO}_{x}\right)$, and the other one for the chemical dissolution of the same oxide in the same electrolyte [19]:

$$
\begin{array}{r}
\mathrm{Me}+x \mathrm{H}_{2} \mathrm{O} \longrightarrow \mathrm{MeO}_{x}+2 x \mathrm{H}^{+}+2 e x^{-} \\
\Delta G_{\mathrm{el}} \\
\mathrm{MeO}_{x}+2 x \mathrm{H}^{+}+n E^{-} \longrightarrow\left[\mathrm{MeE}_{n}\right]^{n-2 x}+2 x \mathrm{H}+x \mathrm{H}_{2} \mathrm{O} \\
\Delta G_{\mathrm{ch}}
\end{array}
$$

Equation (1) represents the electrochemical anodic reaction. The change of its free energy is governed by the Nernst equation and is the function of the electrode potential, which determines the metal ability to be transformed in the electrolyte into the ionic form:

$$
\Delta G_{\mathrm{el}}=-z F E,
$$

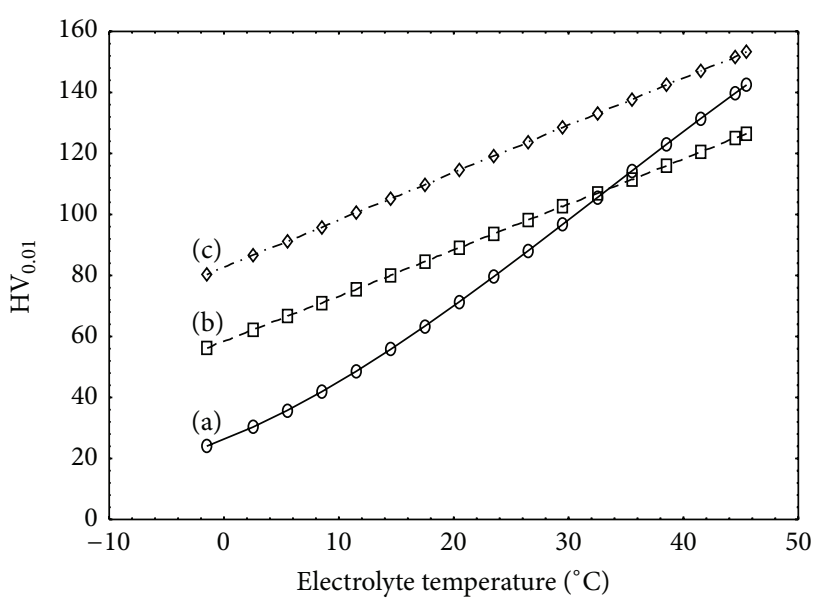

Figure 12: The dependence of the layer microhardness on the temperature of the electrolyte: $c\left(\mathrm{H}_{2} \mathrm{SO}_{4}\right)=1.99 \mathrm{~mol} \cdot \mathrm{L}^{-1}, c\left(\mathrm{C}_{2} \mathrm{H}_{2} \mathrm{O}_{4}\right)=$ $0.06 \mathrm{~mol} \cdot \mathrm{L}^{-1}, U=13.5 \mathrm{~V}, t=20 \mathrm{~min}$. (a) $1 \mathrm{~A} \cdot \mathrm{dm}^{-2}$, (b) $3 \mathrm{~A} \cdot \mathrm{dm}^{-2}$, and (c) $5 \mathrm{~A} \cdot \mathrm{dm}^{-2}$.

where $z$ is the number of electrons transferred, $F$ is the Farraday constant, and $E$ is the electrode potential which is affected by the applied voltage. Equation (2) expresses a chemical reaction with the change of a free energy $\Delta G_{\mathrm{ch}}$ in a constant value regardless of the applied voltage. Due to the increasing temperature of the electrolyte, a predominance of a chemical dissolution occurs. The increase in the current density generally leads to the increase in the layer thickness and consequently to the rise of the heat at the oxideelectrolyte interface [14].

These effects can generate larger gradients of the electrolyte temperature and a composition along the deeper pore walls with possible favourable effects on the oxide dissolution and adsorption of sulfate anions on the pore walls [20]. In addition, a higher driving force accelerates the reactions at the substrate-oxide interface and consequently the appearance of defects. These local effects are expected to decrease the microhardness of anodic oxide layers [14].

For the current densities of $3 \mathrm{~A} \cdot \mathrm{dm}^{-2}$ and $5 \mathrm{~A} \cdot \mathrm{dm}^{-2}$, the electrolyte temperature is significant only in interactions with the molar concentration of sulfuric acid, voltage, and the anodizing time. It can be assumed that the decrease in the layer microhardness is caused, besides the increasing temperature, also by the prolonged period of the anodizing. With long periods of anodic oxidation, the conditions for the generated layer dissolving are created. This dissolution etches the layer and significantly worsens the mechanical and utility properties of the generated layer.

The dependence of the layer microhardness on the change of the electrolyte temperature with the anodizing time of $1.22 \mathrm{~min}$ is shown in Figure 7. At the current density of $1 \mathrm{~A} \cdot \mathrm{dm}^{-2}$, two areas of the change to the microhardness development are observed. Within the interval $-1.5^{\circ} \mathrm{C}$ to $11.5^{\circ} \mathrm{C}$, the reduction in microhardness occurs. This effect can be attributed to a combination of the electrolyte low temperature, a low voltage, and a short anodizing time. Due to the increasing temperature of the electrolyte above 
$11.5^{\circ} \mathrm{C}$, there is a sharp increase in the layer microhardness. The temperature rise of $1^{\circ} \mathrm{C}$ corresponds to a microhardness increase of $2.2 \%$. At the current density of $3 \mathrm{~A} \cdot \mathrm{dm}^{-2}$, the increasing values of the layer microhardness along with the growth of the electrolyte temperature can be observed. The average increase in the microhardness value within the range of the electrolyte temperature $-1.5^{\circ} \mathrm{C}$ to $45.5^{\circ} \mathrm{C}$ is $62 \%$. The increase in the current density to $5 \mathrm{~A} \cdot \mathrm{dm}^{-2}$ has no significant effect on the change in the value of the layer microhardness depending on the electrolyte temperature.

The effect of the electrolyte temperature on the layer microhardness with the anodizing time of $25 \mathrm{~min}$ is shown in Figure 8 . With the current density of $1 \mathrm{~A} \cdot \mathrm{dm}^{-2}$, there is the increase in the microhardness value within the entire range of the electrolyte temperature. The change of the temperature from $-1.5^{\circ} \mathrm{C}$ to $45.5^{\circ} \mathrm{C}$ will increase the microhardness by almost $65 \%$. At the current density of $3 \mathrm{~A} \cdot \mathrm{dm}^{-2}$, a significant decrease in the microhardness value along with the increase of the electrolyte temperature is observed. It can be assumed that the increase of the anodizing time to $25 \mathrm{~min}$, by the increasing temperature of the electrolyte, the conditions for a generated layer dissolving are created. The reduction in the layer microhardness in $1.5 \%$, according to the results of the experiment, corresponds to the increase of the electrolyte temperature of $1^{\circ} \mathrm{C}$. A further increase in the current density to $5 \mathrm{~A} \cdot \mathrm{dm}^{-2}$ does not result in the change of the layer microhardness value due to the changes in the electrolyte temperature. Microhardness in the whole range of the electrolyte temperatures $\left(-1.5^{\circ} \mathrm{C}\right.$ to $\left.45.5^{\circ} \mathrm{C}\right)$ will be changed only by $2.8 \%$.

With the anodizing time of $48.78 \mathrm{~min}$, the dependence of the layer microhardness on the change of the electrolyte temperature can be seen in Figure 9.

With the current density of $1 \mathrm{~A} \cdot \mathrm{dm}^{-2}$, the dependence of the layer microhardness on the electrolyte temperature may be divided into two areas: the area of the increase of the layer microhardness and the area of the decrease of the microhardness value. These areas can be separated by the value of a critical temperature. Experimentally identified dependence of the microhardness change on the temperature of the electrolyte at the current density of $1 \mathrm{~A} \cdot \mathrm{dm}^{-2}$, for the specific conditions of the anodic oxidation $\left(c\left(\mathrm{H}_{2} \mathrm{SO}_{4}\right)\right.$ $=1.43 \mathrm{~mol} \cdot \mathrm{L}^{-1}, c\left(\mathrm{C}_{2} \mathrm{H}_{2} \mathrm{O}_{4}\right)=0.06 \mathrm{~mol} \cdot \mathrm{L}^{-1}, U=10 \mathrm{~V}, t=$ $48.78 \mathrm{~min})$, can be expressed in the form:

$$
\begin{aligned}
\mathrm{HV}_{0.01 ; 1 \mathrm{~A} \cdot \mathrm{dm}^{-2}=} & 65.58+3.803 \cdot T-0.038 \cdot T^{2}-4.35 \\
& \cdot 10^{-4} \cdot T^{3}
\end{aligned}
$$

Local extremes of the function are calculated if the first derivative of (4) is equal to zero:

$$
\frac{d\left(\mathrm{HV}_{0.01 ; 1 \mathrm{~A} \cdot \mathrm{dm}^{-2}}\right)}{d T}=0 \text {. }
$$

By the solution to (5), we will obtain the stationary points, namely, $T_{1}=-90.41^{\circ} \mathrm{C}$ and $T_{2}=32.17^{\circ} \mathrm{C}$. Since the temperature range (Table 2 ) is $-1.78^{\circ} \mathrm{C}$ to $48.78^{\circ} \mathrm{C}$, the value $T_{2}$ will be considered a permissible solution. Substituting the value from the interval $\left\langle-1.78^{\circ} \mathrm{C}, T_{2}\right)$ to (5), the first derivative is greater than zero; that is, the function (4) on the interval $\left\langle-1.78^{\circ} \mathrm{C}, T_{2}\right)$ is increasing. Substituting the value from the interval $\left(T_{2}, 48.78^{\circ} \mathrm{C}\right)$ to $(5)$, the first derivative is less than zero; that is, the function (4) on the interval $\left\langle-1.78^{\circ} \mathrm{C}, T_{2}\right.$ ) is decreasing. The value $T_{2}$ is thus a local maximum of the function (4) and at this temperature the layer microhardness reaches the maximum value; that is, $\mathrm{HV}_{0.01}=134$. In the area below the critical temperature $T_{2}$, the growth rate of the layer microhardness depending on the temperature is on average $55 \%$. In the area above the critical temperature, the rate of the decrease in the layer microhardness is $12.8 \%$. At the current density of $3 \mathrm{~A} \cdot \mathrm{dm}^{-2}$, due to the increase in the electrolyte temperature, the decrease in the layer microhardness occurs. The average rate of the decrease in the layer microhardness value within the range of experimental temperatures of the electrolyte is $691 \%$. At the current density of $5 \mathrm{~A} \cdot \mathrm{dm}^{-2}$, only a minimum effect of the electrolyte temperature on the layer microhardness value is observed. The growth rate of the layer microhardness is $1.8 \%$.

Another important factor that influences the anodic layer formation is the voltage. The voltage significantly affects the mechanical properties of the layer as well as the layers microhardness. Figures 10-12 show the dependence of the layer microhardness on the temperature of the electrolyte with the voltage changes for the current densities of $1 \mathrm{~A} \cdot \mathrm{dm}^{-2}$, $3 \mathrm{~A} \cdot \mathrm{dm}^{-2}$, and $5 \mathrm{~A} \cdot \mathrm{dm}^{-2}$. The dependence of the layer microhardness on the electrolyte temperature at the voltage of $8.5 \mathrm{~V}$ is shown in Figure 10.

At the current density of $1 \mathrm{~A} \cdot \mathrm{dm}^{-2}$, a slight decrease in the layer microhardness value within the range $-1.78^{\circ} \mathrm{C}$ to $11.5^{\circ} \mathrm{C}$ is observed. This decrease in the layer microhardness is about $2.3 \%$. Under these conditions of the anodizing, the electrolyte conductivity is too low. The applied voltage refers to the situation when $\Delta G_{\mathrm{ch}}$ is always lower than $\Delta G_{\mathrm{el}}$. In this case, the oxide is generated based on (1), but it is unstable and immediately dissolves due to the reaction (2). This case is referred to as electrochemical etching. The electrolyte temperature rise above the temperature of $11.5^{\circ} \mathrm{C}$ results in the increased value of the layer microhardness. This growth represents an average of $42.8 \%$. The increasing temperature of the electrolyte leads to a significant change in the electrolyte conductivity and, even at a low voltage, a stable layer is generated. At the current density of $3 \mathrm{~A} \cdot \mathrm{dm}^{-2}$, due to the increasing temperature of the electrolyte, a decrease in the layer microhardness occurs. A further increase in the current density to $5 \mathrm{~A} \cdot \mathrm{dm}^{-2}$ leads to the increase in the layer microhardness due to the temperature rise. This growth throughout the entire interval of the experimentally applied temperatures is about $17 \%$. The voltage of $8.5 \mathrm{~V}$ is not used in practical applications. In the paper, it was used only for the comparison of the emerging changes of the layer microhardness.

The voltage increase up to $10.5 \mathrm{~V}$ when analyzing the changes in the layer microhardness due to the effect of the electrolyte temperature is in Figure 11. At the current density of $1 \mathrm{~A} \cdot \mathrm{dm}^{-2}$, within the whole range of the applied temperatures of the electrolyte, there is the increase in 
the microhardness value. This growth is about $73 \%$. Compared with the course of the dependence of the layer microhardness on the influence of the electrolyte temperature at a voltage of $8.5 \mathrm{~V}$ and the temperature of $-1.78^{\circ} \mathrm{C}$, the decrease in the value of microhardness is $35 \%$. When increasing the temperature of the electrolyte to $48.78^{\circ} \mathrm{C}$, at the voltage of $10.5 \mathrm{~V}$, there occurs the increase in the microhardness value of $34 \%$ when compared to the layer microhardness at the voltage of $8.5 \mathrm{~V}$. With the current density of $3 \mathrm{~A} \cdot \mathrm{dm}^{-2}$, there is a small decrease in the value of the layer microhardness due to the electrolyte temperature increase of $8.4 \%$. Due to the voltage increase of $2 \mathrm{~V}$, the value of the layer microhardness with the electrolyte temperature of $-1.78^{\circ} \mathrm{C}$ will increase by $10 \%$ and with the electrolyte temperature of $48.78^{\circ} \mathrm{C}$ by almost $94 \%$. The increase of the current density to $5 \mathrm{~A} \cdot \mathrm{dm}^{-2}$ leads to the growth in the value of the layer microhardness depending on the temperature of about $15 \%$.

The dependence of the layer microhardness on the temperature of the electrolyte at the voltage of $13.5 \mathrm{~V}$ can be seen in Figure 12. With all the current densities, the increase in the layer microhardness along with the increasing electrolyte temperature can be observed. The voltage magnitude is therefore sufficient to form a stable oxide regardless of the current density. Based on (1) and (2), the courses of $\Delta G_{\mathrm{ch}}$ and $\Delta G_{\mathrm{el}}$ intersect at some point. In this case, depending on the voltage, the progressions of $\Delta G_{\mathrm{ch}}$ and $\Delta G_{\mathrm{el}}$ can be divided into three areas with two critical values. $U_{0}$ is the applied voltage, when $\Delta G_{\mathrm{el}}(E)=0$ and $U^{*}$ is the voltage at which $\Delta G_{\mathrm{ch}}=\Delta G_{\mathrm{el}}$. When satisfying the condition $U_{0} \geq U^{*}$, at the anodic oxidation, there is a stable oxide layer present in the electrolyte, which, by the anodic voltage, is protected against the dissolution according to the chemical reaction (2). At the current density of $1 \mathrm{~A} \cdot \mathrm{dm}^{-2}$, the growth rate of the layer microhardness value according to the change in the electrolyte temperature within the whole interval is on average $83 \%$. Increasing the current density to $3 \mathrm{~A} \cdot \mathrm{dm}^{-2}$, the growth rate of the value of the layer microhardness depending on the temperature drops approximately to $56 \%$. In the temperature range of more than $36^{\circ} \mathrm{C}$, the layer microhardness value is higher at $1 \mathrm{~A} \cdot \mathrm{dm}^{-2}$ than at the current density of $3 \mathrm{~A} \cdot \mathrm{dm}^{-2}$ by $8 \%$. At the current density of $5 \mathrm{~A} \cdot \mathrm{dm}^{-2}$, the layer microhardness achieves the highest values along with the increasing temperature of the electrolyte. The growth of the microhardness values is $47 \%$. We observe that the electrolyte temperature has a significant impact on the microhardness values at the voltage as high as $13.5 \mathrm{~V}$.

\section{Conclusions}

In the paper, the effect of the electrolyte temperature on the change of the layer microhardness values formed by the anodic aluminium oxidation has been evaluated. The electrolyte was composed of $\mathrm{H}_{2} \mathrm{SO}_{4}$ and $\mathrm{C}_{2} \mathrm{H}_{2} \mathrm{O}_{4}$. It has been demonstrated that the increase in the electrolyte temperature leads to the growth of the layer microhardness value at the current density of $1 \mathrm{~A} \cdot \mathrm{dm}^{-2}$. With the anodizing time of $48.78 \mathrm{~min}$, it is, however, possible to define the critical temperature at which the change in the electrolyte temperature effect on the values of the layer microhardness occurs. An average growth of the layer microhardness values depending on the temperature at the current density of $1 \mathrm{~A} \cdot \mathrm{dm}^{-2}$ is $66 \%$. With the increasing amount of sulfuric acid in the electrolyte, however, the growth of the layer microhardness decreases by about $24 \%$. Along with the concurrent effect of the anodizing time within the interval of $1.22 \mathrm{~min}$ to $25 \mathrm{~min}$, there is the growth of the layer microhardness value depending on the electrolyte temperature of $5 \%$. Increasing the anodic oxidation time to more than 25 minutes, there occurs a decline in the value of the layer microhardness of about $4 \%$. The increasing voltage leads to the growth of the layer microhardness depending on the temperature of the electrolyte of almost 39\%. At the current density of $3 \mathrm{~A} \cdot \mathrm{dm}^{-2}$, the layer microhardness decreases due to the temperature along with the increasing molar concentration of sulfuric acid. The growth of the layer microhardness value was observed when the anodizing time was $25 \mathrm{~min}$. Above and below this time, a reduction in the layer microhardness value due to the temperature of the electrolyte occurs. At the current density of $5 \mathrm{~A} \cdot \mathrm{dm}^{-2}$, the effect of the electrolyte temperature on the change of the layer microhardness value is not significant. The growth in the value of the layer microhardness occurs only at the voltage higher than $10.5 \mathrm{~V}$.

The process of anodic aluminium oxidation is a complex process. There are many factors operating simultaneously to change the value of the layer microhardness. It is therefore necessary to consider the impact of these operating factors when examining the changes in the layers parameters. As shown under various conditions of the anodizing, the layer microhardness depending on the temperature and the current density changed differently. Exploring these dependencies, it is possible to generate the layers with the required quality parameters.

\section{Conflict of Interests}

The authors declare that there is no conflict of interests regarding the publication of this paper.

\section{Acknowledgments}

The research work was supported by the Project of the Structural Funds of the EU "Research and Development of the Intelligent Non-conventional Actuators Based on Artificial Muscles," ITMS code: 26220220103, and also it is supported by Grant VEGA 1/0738/14 "The Study of Corrosion Resistance of Coated Steel Sheets for Use in Automotive Industry" of Scientific Grant Agency of the Ministry of Education of Slovak Republic and the Slovak Academy of Sciences.

\section{References}

[1] J. A. González, E. Escudero, V. López, J. Simancas, and M. Morcillo, "Durability of bare and anodised aluminium in atmosphere of very different corrosivities. I. Bare aluminium," Revista de Metalurgia (Madrid), vol. 40, no. 4, pp. 259-269, 2004. 
[2] V. López, E. Escudero, J. A. González, E. Otero, and M. Morcillo, "Durability of bare and anodised aluminium in atmosphere of very different corrosivities. II. Anodised aluminium," Revista de Metalurgia, vol. 40, no. 4, pp. 270-279, 2004.

[3] D. AlMawlawi, N. Coombs, and M. Moskovits, "Magnetic properties of $\mathrm{Fe}$ deposited into anodic aluminum oxide pores as a function of particle size," Journal of Applied Physics, vol. 70, no. 8, pp. 4421-4425, 1991.

[4] N. Haberkorn, J. S. Gutmann, and P. Theato, "Templateassisted fabrication of free-standing nanorod arrays of a holeconducting cross-linked triphenylamine derivative: toward ordered bulk-heterojunction solar cells," ACS Nano, vol. 3, no. 6, pp. 1415-1422, 2009.

[5] G. Gorokh, A. Mozalev, D. Solovei, V. Khatko, E. Llobet, and X. Correig, "Anodic formation of low-aspect-ratio porous alumina films for metal-oxide sensor application," Electrochimica Acta, vol. 52, no. 4, pp. 1771-1780, 2006.

[6] J. H. Holtz and S. A. Asher, "Polymerized colloidal crystal hydrogel films as intelligent chemical sensing materials," Nature, vol. 389, no. 6653, pp. 829-832, 1997.

[7] M. Deubel, G. von Freymann, M. Wegener, S. Pereira, K. Busch, and C. M. Soukoulis, "Direct laser writing of three-dimensional photonic-crystal templates for telecommunications," Nature Materials, vol. 3, no. 7, pp. 444-447, 2004.

[8] G. Sauer, G. Brehm, S. Schneider et al., "Highly ordered monocrystalline silver nanowire arrays," Journal of Applied Physics, vol. 91, no. 5, pp. 3243-3247, 2002.

[9] A. Santos, L. Vojkuvka, J. Pallarés, J. Ferré-Borrull, and L. F. Marsal, "Cobalt and nickel nanopillars on aluminium substrates by direct current electrodeposition process," Nanoscale Research Letters, vol. 4, no. 9, pp. 1021-1028, 2009.

[10] B. A. Scott, "Decorative and protective finishes produced on aluminium by hard anodizing," Transactions of the Institute of Metal Finishing, vol. 43, p. 1, 1965.

[11] S. Koizumi, S. Ninagawa, and S. J. Ueda, "Studies on wear resistance of anodic oxide films on aluminium by means of taber abraser," Journal of the Metal Finishing Society of Japan, vol. 19, no. 12, pp. 504-510, 1968.

[12] K. Okubo, "Anodizing high-strength and free-cutting aluminum alloys," Metal Finishing, vol. 81, no. 11, pp. 63-66, 1983.

[13] A. P. Gruaro and D. R. Gabe, "AC anodizing of aluminium in modified sulphuric acid: the effect of temperature," Transactions of the Institute of Metal Finishing, vol. 63, p. 1, 1985.

[14] L. E. Fratila-Apachitei, J. Duszczyk, and L. Katgerman, "Vickers microhardness of $\mathrm{AlSi}(\mathrm{Cu})$ anodic oxide layers formed in $\mathrm{H}_{2} \mathrm{SO}_{4}$ at low temperature," Surface and Coatings Technology, vol. 165, no. 3, pp. 309-315, 2003.

[15] R. W. Thomas, "Measurement of hardness, wear index and abrasion resistance of anodic coating on aluminum," Transactions of the Institute of Metal Finishing, vol. 59, pp. 97-103, 1981.

[16] P. Chowdhury, K. Raghuvaran, M. Krishnan, H. C. Barshilia, and K. S. Rajam, "Effect of process parameters on growth rate and diameter of nano-porous alumina templates," Bulletin of Materials Science, vol. 34, no. 3, pp. 423-427, 2011.

[17] A. Zahariev and A. Girginov, "Formation of complex anodic films on porous alumina matrices," Bulletin of Materials Science, vol. 26, no. 3, pp. 349-353, 2003.

[18] Ž. Holická, M. Chovancová, and M. Zemanová, "Anodic oxidation of aluminium in acidic electrolytes," Chemicke Listy, vol. 94, no. 12, pp. 1081-1086, 2000.
[19] M. Wang, Y. Liu, and H. Yang, "A unified thermodynamic theory for the formation of anodized metal oxide structures," Electrochimica Acta, vol. 62, pp. 424-432, 2012.

[20] J. Rasmussen, "New insights into the microhardness of anodized aluminum," Metal Finishing, vol. 99, no. 9, pp. 46-51, 2001. 

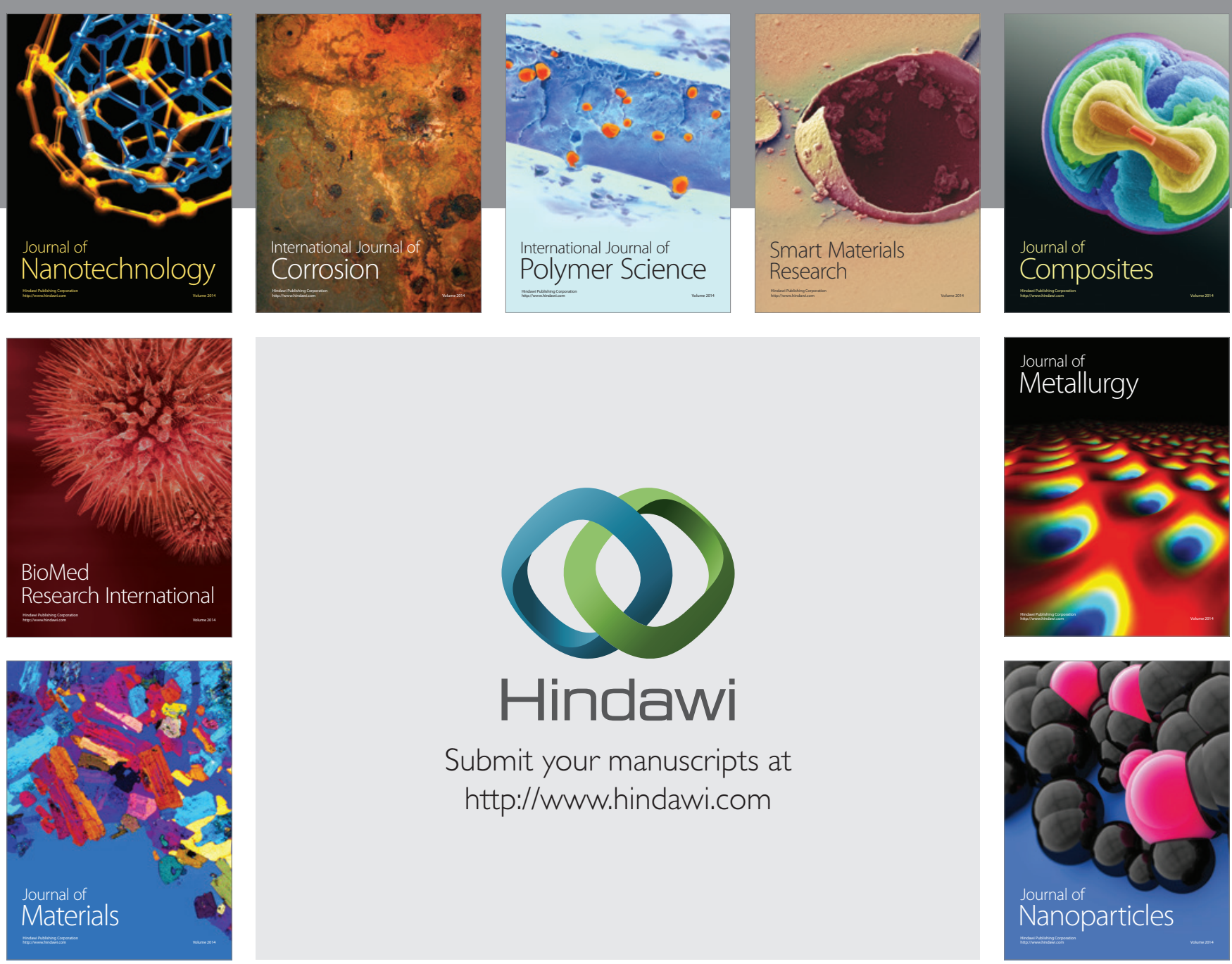

Submit your manuscripts at http://www.hindawi.com
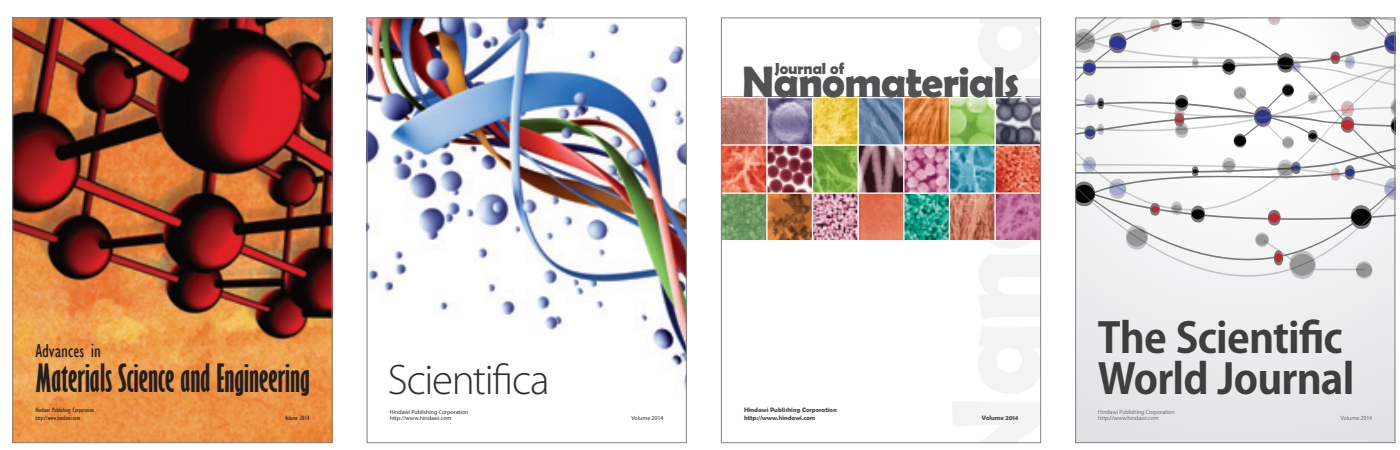

\section{The Scientific World Journal}
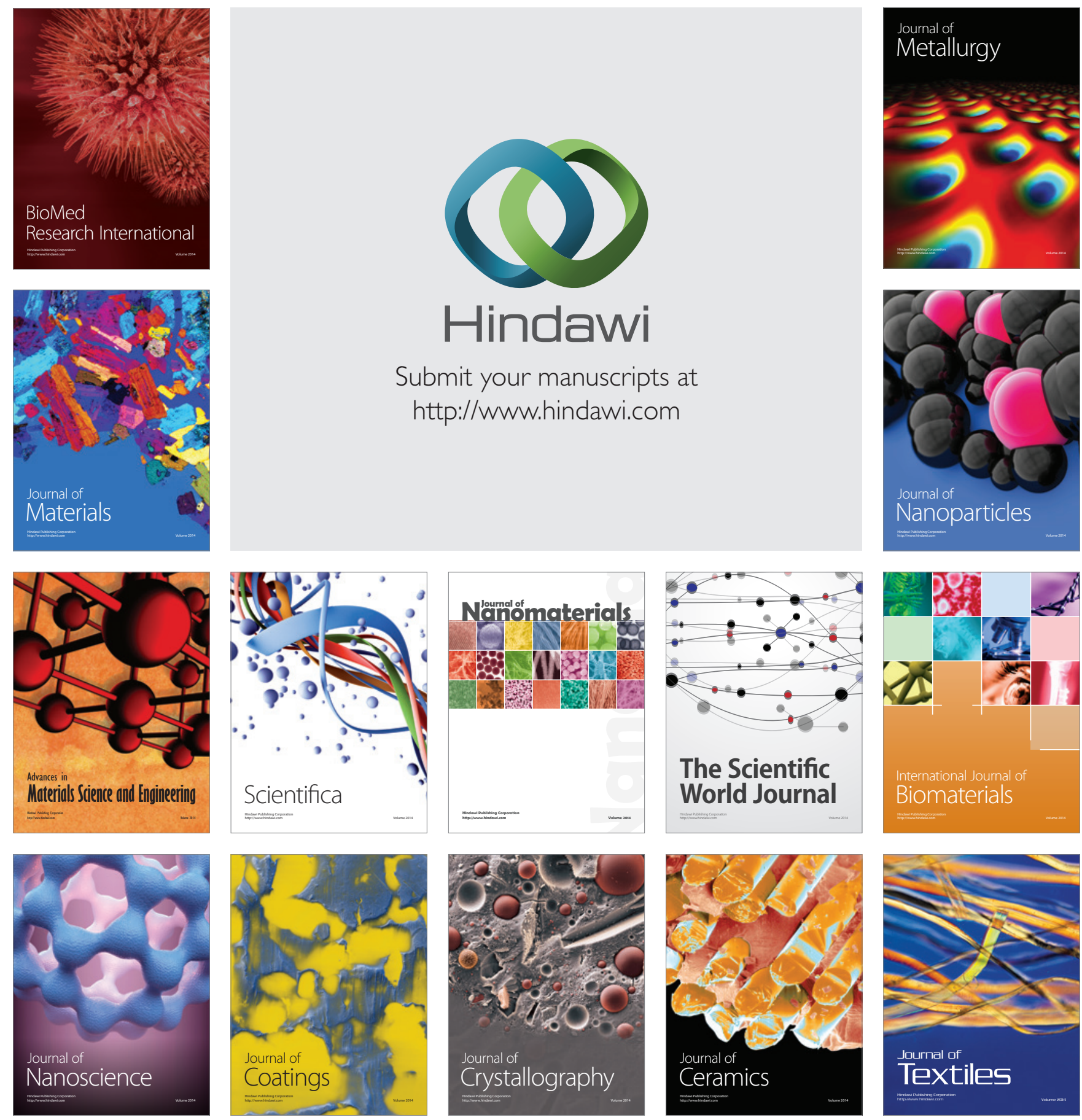